\title{
Transferable integrons of Gram-negative bacteria isolated from the gut of a wild boar in the buffer zone of a national park
}

\author{
Joanna Mokracka • Ryszard Koczura • \\ Adam Kaznowski
}

Received: 10 June 2011 / Accepted: 29 September 2011 /Published online: 21 October 2011

(C) The Author(s) 2011. This article is published with open access at Springerlink.com

\begin{abstract}
The aim of this study was to determine the presence of integron-bearing Gram-negative bacteria in the gut of a wild boar (Sus scrofa L.) shot in the buffer zone of a national park. Five Gram-negative strains of Escherichia coli, Serratia odorifera, Hafnia alvei and Pseudomonas sp. were isolated. Four of these strains had class 2 integrase (intI2), and one harbored class 1 integrase (intI1). The integron-positive strains were multiresistant, i.e., resistant to at least three unrelated antibiotics. All of the integrons were transferred to $E$. coli $\mathrm{J}-53\left(\mathrm{Rif}^{\mathrm{R}}\right)$ in a conjugation assay. The results showed that a number of multiresistant, integron-containing bacterial strains of different genera may inhabit a single individual of a wild animal, allowing the possibility of transfer of antimicrobial resistance genes.
\end{abstract}

Keywords Integrons $\cdot$ Antibiotic resistance $\cdot$ Horizontal gene transfer

\section{Introduction}

Extensive and uncontrolled use of antibiotics in medication, veterinary, agriculture, aquaculture and farming has resulted in the appearance of antibiotic resistant bacteria in the environment. Resistance genes and resistant bacteria in the environment are considered an ecological problem (Levy and Marshall 2004). Thus, the routes of their dissemination should be monitored. Integrons are natural bacterial gene

\footnotetext{
J. Mokracka $(\square) \cdot$ R. Koczura $\cdot$ A. Kaznowski

Department of Microbiology, Faculty of Biology,

Adam Mickiewicz University,

ul. Umultowska 89,

61-614 Poznań, Poland

e-mail: amok@amu.edu
}

capture systems that are considered responsible for multiresistance, i.e., resistance towards at least three antibiotics belonging to different chemical groups. The integron platform covers DNA fragments that consists of an integrase gene of the tyrosine recombinase family, a primary recombination site called the attI, and a promoter $\mathrm{P}_{\mathrm{C}}$ that directs transcription of the captured genes (Hall and Collis 1995). Integron-encoded integrase can recombine discrete units of circularized DNA known as gene cassettes. As the integron system has the ability to create novel combinations of resistance genes, it could represent a dynamic force in the evolution of multidrug resistant bacteria. Integrons are linked to mobile DNA elements such as transposons and conjugative plasmids that enable horizontal spread through bacterial populations (Fluit and Schmitz 2004). Five classes of resistance integrons have been defined based on nucleotide sequence similarity of their integrase genes. Class 1 integrons are most ubiquitous among Gram-negative bacteria, but have been reported in Gram-positive bacteria such as Mycobacterium sp. Corynebacterium sp., and Enterococcus sp., class 2 integrons possess a defective integrase gene and are associated with $\operatorname{Tn} 7$ family of transposons, and class 3 integrons have been found in Serratia marcescens, Alcaligenes xylosidans, Klebsiella pneumoniae, Pseudomonas putida, P. aeruginosa (Fluit and Schmitz 2004; Mazel 2006; Márquez et al. 2008). The fourth and fifth class has been identified in Vibrio species (Mazel 2006).

Integrons can be transferred between cells of the same or different species in one genetic event, leading to resistance in bacterial strains that were previously susceptible. Moreover, integron-mediated resistance can be silenced in bacterial population at no biological cost, which means that resistant bacteria may persist even if the selective pressure imposed by antibiotic usage is reduced (Allen et al. 2010). 
In the present study we searched for the presence of integron-bearing Gram-negative bacteria in the gut of a wild boar (Sus scrofa L.) shot in the buffer zone of Drawieński National Park in Poland.

\section{Materials and methods}

Bacterial isolation and determination of integron presence

Bacteria from the intestine sample of a shot wild boar were isolated on MacConkey agar no. 3 (Oxoid). Integrons were detected in bacterial genomic DNA by the multiplex PCR method according to Dillon et al. (2005). Integron-positive strains were then identified with API 20E or API 20NE (BioMérieux, Craponne, France) and by sequencing $16 \mathrm{~S}$ rDNA. To determine whether strains belonging to the same species were genetically similar, a rep-PCR with starters REP1R (5'-IIIICGICGICATCIGGC-3') and REP2I (5'ICGICTTATCIGGCCTAC-3') was performed to amplify repetitive extragenic palindromic sequences (Versalovic et al. 1991). The PCR reaction consisted of an initial denaturation for $7 \mathrm{~min}$ at $95^{\circ} \mathrm{C}$ and 30 cycles of $30 \mathrm{~s}$ at $94^{\circ} \mathrm{C}, 30 \mathrm{~s}$ at $40^{\circ} \mathrm{C}$ and $30 \mathrm{~s}$ at $65^{\circ} \mathrm{C}$ followed by a final extension step of $16 \mathrm{~min}$ at $65^{\circ} \mathrm{C}$. Electrophoretic patterns of the products were analyzed by using Gel Compar II 3.5 software (Applied Maths; http://www.applied-maths.com) with Dice coefficient and the UPGMA method.

Analysis of variable parts of integrons

Variable parts of class 1 and class 2 integrons were amplified using primers complementary to the $5^{\prime}$ and $3^{\prime}$ conserved regions of the class 1 (5'-CS; 3'-CS) and class 2 (Hep54 and Hep71) integrons. The primer sequences have been published elsewhere (Lévesque et al. 1995; White et al. 2001). PCR amplifications were conducted as follow: initial denaturation at $94^{\circ} \mathrm{C}$ for $5 \mathrm{~min}$, and 30 cycles of $94^{\circ} \mathrm{C}$ for $1 \mathrm{~min}, 55^{\circ} \mathrm{C}$ for $1 \mathrm{~min}, 72^{\circ} \mathrm{C}$ for $5 \mathrm{~min}$, and final elongation at $72^{\circ} \mathrm{C}$ for $8 \mathrm{~min}$.

Variable parts of the integrons as well as class 2 integrase gene amplicons were sequenced in a 3130xl Genetic Analyzer (Applied Biosystems, Foster City, CA). Sequence data were analyzed with DNA Baser (Heracle Software; http://www.dnabaser.com) and aligned with available GenBank data using Nucleotide BLAST (Basic Local Alignment Search Tool; http://blast.ncbi.nlm.nih.gov/ Blast.cgi). A gene cassette was identified if the similarity with GenBank data was equal to or higher than $95 \%$. The PCR reactions were done in a $\mathrm{C} 1000^{\mathrm{TM}}$ Thermal Cycler (BioRad, Hercules, CA). The products were separated in a $1.5 \%$ agarose gel. The molecular weight of PCR products was determined with Bio-Capt MW software (Vilber Lourmat, Marne La Vallée, France).

\section{Antibiotic resistance}

Antibiotic resistance patterns were determined by agar disc diffusion test according to The European Committee on Antimicrobial Susceptibility Testing (EUCAST 2011). The quality control strain used in the study was Escherichia coli ATCC 25922. The isolates were tested for susceptibility to 27 antibiotics: amikacin, amoxycyllin/clavulanic acid, ampicillin, aztreonam, cefoperazone, cefotaxime, ceftazidime, cefuroxime, cephalotin, cephazolin, chloramphenicol, ciprofloxacine, co-trimoxazole, gentamicin, imipenem, kanamycin, netilmicin, nitrofurantoine, norfloxacin, piper-

Table 1 Characteristics of integrons and antibiotic resistance patterns of bacterial strains isolated from wild boar gut

\begin{tabular}{|c|c|c|c|c|c|c|}
\hline $\begin{array}{l}\text { Strain } \\
\text { no. }\end{array}$ & Species & Integrase & $\begin{array}{l}\text { Size of the } \\
\text { integron's } \\
\text { variable part }\end{array}$ & Gene cassette & Antibiotic resistance pattern & $\begin{array}{l}\text { Antibiotic resistance pattern } \\
\text { of transconjugant }\end{array}$ \\
\hline $\mathrm{D} 1 / 5$ & Hafnia alvei & intI2 & $1.6 \mathrm{~kb}$ & sat2-aadA1 & $\begin{array}{l}\text { STR }^{\mathrm{a}}, \mathrm{CHL}, \mathrm{PIP}, \mathrm{CAZ}, \mathrm{SUL}, \\
\text { TMP, TET }\end{array}$ & $\begin{array}{l}\text { STR, CHL, PIP, CAZ, SUL, TMP, } \\
\text { TET, RIF }\end{array}$ \\
\hline $\mathrm{D} 1 / 7$ & $\begin{array}{l}\text { Escherichia } \\
\text { coli }\end{array}$ & intI2 & $1.6 \mathrm{~kb}$ & sat2-aadA1 & $\begin{array}{l}\text { STR, CHL, TIC, CIP, NOR, CTX, } \\
\text { SUL, TMP, SXT, TET, ATM }\end{array}$ & $\begin{array}{l}\text { STR, CHL, TIC, CTX, SUL, TMP, } \\
\text { SXT, TET, ATM, RIF }\end{array}$ \\
\hline $\mathrm{D} 2 / 2$ & E. coli & intI2 & $1.9 \mathrm{~kb}$ & dfrA1-sat2-aadA1 & $\begin{array}{l}\text { STR, CTX, TIC, SUL, TMP, } \\
\text { SXT, TET }\end{array}$ & $\begin{array}{l}\text { STR, CTX, TIC, SUL, TMP, SXT, } \\
\text { TET, RIF }\end{array}$ \\
\hline $\mathrm{D} 3 / 1$ & $\begin{array}{l}\text { Serratia } \\
\quad \text { odorifera }\end{array}$ & intI2 & $1.6 \mathrm{~kb}$ & sat2-aadA1 & $\begin{array}{l}\text { STR, NET, CHL, TIC, CAZ, CTX, } \\
\text { SUL, TMP, SXT, TET, ATM }\end{array}$ & $\begin{array}{l}\text { STR, NET, CHL, TIC, CAZ, CTX, } \\
\text { SUL, TMP, SXT, TET, ATM, RIF }\end{array}$ \\
\hline D5/4 & $\begin{array}{l}\text { Pseudomonas } \\
\text { sp. }\end{array}$ & intI1 & $0.18 \mathrm{~kb}$ & None & $\begin{array}{l}\text { STR, NET, TIC, CTX, CFP, SUL, } \\
\text { TMP, SXT, ATM }\end{array}$ & $\begin{array}{l}\text { STR, NET, TIC, CTX, CFP, SUL, } \\
\text { TMP, SXT, ATM, RIF }\end{array}$ \\
\hline
\end{tabular}

${ }^{a}$ Antibiotics: $A T M$ aztreonam, $C A Z$ ceftazidime, $C F P$ cefoperazone, $C H L$ chloramphenicol, $C I P$ ciprofloxacin, $C T X$ cefotaxime, $N E T$ netilmicin, NOR norfloxacin, PIP piperacillin, RIF rifampicin, STR streptomycin, SUL sulfamethoxazole, SXT sulfamethoxazole + trimethoprim, TET tetracycline $T I C$ ticarcillin, TMP trimethoprim, TZP piperacillin + tazobactam

b The recipient strain $E$. coli $\mathrm{J}-53$ is resistant to rifampicin 
acillin, piperacillin/tazobactam, streptomycin, sulfamethoxazole, tetracycline, ticarcillin, tobramicin, and trimethoprim. All antibiotic discs were provided by Oxoid.

\section{Conjugation assay}

The transfer capability of integrons was determined in the broth-mating conjugation assay with $E$. coli $\mathrm{J}-53\left(\mathrm{Rif}^{\mathrm{R}}\right)$ as recipient strain (Mokracka et al. 2011). Briefly, overnight cultures of the donor and recipient strain were mixed in equal volumes, grown to mid-exponential phase, plated onto Mueller-Hinton agar plates containing rifampicin and sulfamethoxazole (all donor strains were sulfamethoxazole resistant), and incubated for $24 \mathrm{~h}$ at $30^{\circ} \mathrm{C}$. Transconjugants were identified phenotypically, and the presence of integrons checked by PCR as described above. Plasmid DNA of donor strains and transconjugants was isolated with PureYield ${ }^{\text {TM }}$ Plasmid Mini Prep System (Promega, Madison, WI). All experiments were performed in triplicate.

\section{Results and discussion}

Five isolates recovered from the gut of a wild boar were positive for the presence of an integrase gene and were analyzed further. Four isolates had class 2 integrase (intI2), whereas one harbored class 1 integrase (intII). No class 3 integrons were found. Integrons were found in E. coli (two strains), Hafnia alvei, Serratia odorifera and Pseudomonas sp. (Table 1). Biochemical traits and 16S rDNA sequence allowed identification of the Pseudomonas sp. strain only to the genus level. The two isolates of E.coli had distinct repPCR patterns and were genetically unrelated with a similarity level $52 \%$ (data not shown). The class 2 integrons, which in this study were in the majority, are usually detected less frequently, as most papers report a prevalence of class 1 integrons among intI-positive bacteria isolated from environmental samples (Ahmed et al. 2007; Poeta et al. 2009).

Sequencing of the PCR products of intI2 gene revealed a TAA stop codon at amino acid 179 in all int2-positive isolates, which indicates that the encoded protein was not functional. This is characteristic for intI2; however, exceptions have been reported for Providencia stuartii (Barlow and Gobius 2006) and E. coli (Márquez et al. 2008), which had a glutamine codon at amino acid 179 and produced full-length integrase. The lack of a functional integrase preserves the gene cassette content of class 2 integrons, although their recombination sites may be still recognized by class 1 integrase (Collis et al. 2001).

The sizes of PCR products of variable regions of class 2 integrons ranged from 1.6 to $1.9 \mathrm{~kb}$. The variable regions of class 2 integrons of three strains contained two gene cassettes: sat2 and aadA1, encoding streptothricin acetyltransferase and aminoglycoside-adenyltransferase, respectively. E. coli D2/2 isolate had three cassettes: dfrA1, responsible for resistance to trimethoprim, and sat2 and aadA1 (Table 1). Similar gene cassette arrays in class 2 integrons of $E$. coli isolates recovered from rectal swabs from wild boars in Czech Republic have been reported by Literak et al. (2010).

A 180-bp product of variable region of class 1 integron was noted for Pseudomonas sp. D5/4 strain. This means that there was no integrated gene cassette and the strain had a so-called "zero" integron.

All of the integrons were transferable to E. coli J 53-2 $\left(\mathrm{Rif}^{\mathrm{R}}\right.$ ) by conjugation assay, suggesting that, regardless of class, they were located on transferable elements. Indeed, we found ca. 30-kb plasmids present in both donor strains and tranconjugants of the Enterobacteriaceae strains. The frequency of conjugation ranged between $1.0 \times 10^{-5}$ and $3.5 \times$ $10^{-5}$ per donor strain. This indicates a high possibility of horizontal gene transfer among strains of different genera within the animal's large intestine, and was the likely reason for the occurrence of numerous integron-positive strains in a single animal. Unlike the E. coli $\mathrm{J} 53-2\left(\mathrm{Rif}^{\mathrm{R}}\right)$ recipient, the transconjugants were multiresistant, like the donor strains, i.e., resistant to at least three unrelated antibiotics (Table 1).

In conclusion, in this case study we showed that numerous multiresistant, integron-containing bacterial strains of different genera may inhabit a single individual of a wild animal, with a possibility of transferring antimicrobial resistance genes among them and spreading them to another animal.

Open Access This article is distributed under the terms of the Creative Commons Attribution Noncommercial License which permits any noncommercial use, distribution, and reproduction in any medium, provided the original author(s) and source are credited.

\section{References}

Ahmed AM, Motoi Y, Sato M, Maruyama A, Watanabe H, Fukumoto Y, Shimamoto T (2007) Zoo animals as reservoirs of Gramnegative bacteria harboring integrons and antimicrobial resistance genes. Appl Environ Microbiol 73:6686-6690

Allen HK, Donato J, Wang HH, Cloud-Hansen KA, Davie J, Handelsman J (2010) Call of the wild: antibiotic resistance genes in natural environments. Nat Rev Microbiol 8:251-259

Barlow RS, Gobius KS (2006) Diverse class 2 integrons in bacteria from beef cattle sources. J Antimicrob Chemother 58:1133-1138

Collis CM, Recchia GD, Kim MJ, Stokes HW, Hall RM (2001) Efficiency of recombination reactions catalyzed by class 1 integron integrase IntI1. J Bacteriol 183:2535-2542

Dillon B, Thomas L, Mohmand G, Zelynsky A, Iredell J (2005) Multiplex PCR for screening of integrons in bacterial lysates. J Microbiol Methods 62:221-232 
EUCAST (2011) EUCAST disk diffusion test for routine antimicrobial susceptibility testing. http://www.eucast.org/

Fluit AC, Schmitz FJ (2004) Resistance integrons and super-integrons. Clin Microbiol Infect 10:272-288

Hall RM, Collis CM (1995) Mobile gene cassettes and integrons: capture and spread of genes by site-specific recombination. Mol Microbiol 15:593-600

Lévesque C, Piché L, Larose C, Roy PH (1995) PCR mapping of integrons reveals several novel combinations of resistance genes. Antimicrob Agents Chemother 39:185-191

Levy SB, Marshall B (2004) Antibacterial resistance worldwide: causes, challenges and responses. Nat Med 10:S122-S129

Literak I, Dolejska M, Radimersky T, Klimes J, Friedman M, Aarestrup FM, Hasman H, Cizek A (2010) Antimicrobial-resistant faecal Escherichia coli in wild mammals in central Europe: multiresistant Escherichia coli producing extended-spectrum beta-lactamases in wild boars. J Appl Microbiol 108:1702-1711

Márquez $\mathrm{C}$, Labbate $\mathrm{M}$, Ingold $\mathrm{AJ}$, Chowdhury PR, Ramírez MS, Centrón D, Borthagaray G, Stokes HW (2008) Recovery of a functional class 2 integron from an Escherichia coli strain mediating a urinary tract infection. Antimicrob Agents Chemother 52:4153-4154

Mazel D (2006) Integrons: agents of bacterial evolution. Nat Rev Microbiol 4:608-620

Mokracka J, Koczura R, Pawłowski K, Kaznowski A (2011) Resistance patterns and integron cassette arrays of the Enterobacter cloacae complex strains of human origin. J Med Microbiol 60:737-743

Poeta P, Radhouani H, Pinto L, Martinho A, Rego V, Rodrigues R, Gonçalves A, Rodrigues J, Estepa V, Torres C, Igrejas G (2009) Wild boars as reservoir of extended-spectrum beta-lactamase (ESBL) producing Escherichia coli of different phylogenetic groups. J Basic Microbiol 49:584-588

Versalovic J, Koeuth T, Lupski JR (1991) Distribution of repetitive DNA sequences in eubacteria and application to fingerprinting of bacterial genomes. Nucleic Acids Res 19:6823-6831

White PA, McIver CJ, Rawlinson WD (2001) Integrons and gene cassettes in the Enterobacteriaceae. Antimicrob Agents Chemother 45:2658-2661 